\title{
DESAFIOS DA PESQUISA NO BRASIL uma contribuição ao debate
}

Fórum de RefLeX̃̃o UNIVERSITÁRIA - UNICAMP

\begin{abstract}
Resumo: Esta contribuição analisa a natureza da ciência e a utilização do conhecimento nos países periféricos. Embora o Brasil possua um conjunto expressivo de cientistas de bom nível e injete recursos relativamente vultosos no financiamento à pesquisa, a ciência e a mentalidade científica ainda não estão incorporadas de modo pleno na sociedade. Essa situação deriva, sobretudo, da tremenda exclusão social de grande parte da população.

Palavras-chave: ciência; desenvolvimento; exclusão social.
\end{abstract}

\begin{abstract}
This essay analyzes the nature of science and the use of knowledge in peripheral countries. Although Brazil is home to a significant number of accomplished scientists and invests relatively heavily in research, science and the scientific mentality have still not taken firm root in Brazilian society at large, owing largely to the social exclusion of a sizable portion of the populace.

Key words: science; development; social exclusion.
\end{abstract}

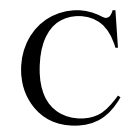

onta-se que o famoso matemático inglês Michael Atiyah resolveu explicar para sua mãe a natureza de suas atividades. Depois de ter ouvido atentamente as explicações do filho, a boa senhora teria dito: "Acho que agora entendi o que você faz; mas diga-me uma coisa, por que pagam você para isso?".

A pergunta que, segundo a anedota, a Sra. Atiyah teria feito a seu filho também é feita com freqüência por políticos, por administradores e pela sociedade em geral. A pertinência de se investirem recursos públicos na pesquisa científica e tecnológica em qualquer país, mas, sobretudo, em países em desenvolvimento como o Brasil, com notáveis carências sociais, deve ser sempre re-demonstrada com argumentos novos e eloqüentes. Nesses tempos, em que a simples aritmética de publicações e citações começa a declinar, é necessário recuperar os argumentos humanistas - que sustentam a nobreza da busca constante pelo conhecimento - e os pragmáticos - que indicam que a pesquisa é a base da inovação, essencial ao desenvolvimento econômico e à geração de riqueza.

Desde a conquista de sua autonomia financeira, a Unicamp vem conseguindo - por meio de mecanismos como o Projeto Qualidade e a avaliação sistemática da produção acadêmica por relatórios trienais de seus docentes - um crescimento contínuo de todos os seus índices de desempenho acadêmico. Os resultados do "provão" na graduação, as últimas avaliações feitas pela Capes dos cursos de pós-graduação e a avaliação dos grupos de pesquisa feita pelo CNPq colocam a Unicamp em posição de grande destaque no panorama nacional. Entretanto, é nesse momento - em que a Unicamp resgata resultados de ações realizadas no passado - que lhe cabe refletir criticamente para apontar reformas e re-direcionamentos que contribuam ao grande debate hoje instalado sobre quanta ciência e de que ciência o Brasil precisa para superar o subdesenvolvimento e aproximar-se dos países avançados. É parte da responsabilidade social das instituições de pesquisa do país, em particular das mantidas com verbas públicas, participar do debate para apontar falhas e limitações do sistema atual e propor melhorias.

\section{EVOLUÇÃO DO PARADIGMA}

Nos últimos quarenta anos a pesquisa científica no Brasil evoluiu significativamente. Diversos foram os fatores e atores que contribuíram para isso. Entretanto, não 
resta a menor dúvida de que parte de tal avanço deva ser creditada à consolidação da política de pós-graduação implantada nos anos 60 nas principais universidades brasileiras.

Para que se tenha uma idéia desse avanço, sem necessidade do uso abusivo de dados estatísticos, que estão disponíveis nas agências financiadoras estaduais e federais, procurar-se-á marcar essa evolução, valendo-se do tipo de pergunta feita nos diferentes momentos até os dias atuais.

$\mathrm{Na}$ década de 60, um professor de uma universidade pública deparava-se com a seguinte pergunta: "Vocêfaz pesquisa?" Uma simples resposta, positiva ou negativa, deixaria seu interlocutor, de certa forma, satisfeito. Em caso positivo, conferiria ao professor interrogado um status diferenciado.

Nos anos 70, a pergunta mudou seu enfoque: "Você tem publicado papers?" Nessa década, o status diferenciado advinha da existência de publicações e, é claro, para aquelas feitas em inglês (mesmo que em periódico nacional), o diferencial positivo seria ainda bem maior.

Os anos 80 já traziam a questão com alguma especificidade: "Com qual temática você está trabalhando? Trata-se de pesquisa básica ou aplicada?" Nessa década, a segunda questão estava no bojo das discussões, levando a debates intermináveis em todos os fóruns em que fosse colocada. Foi um período em que as agências de financiamento, sobretudo as federais, começaram a introduzir mecanismos indutores. Cabe destacar, entre eles, o PADCT, que teve enorme impacto nas áreas de química, física, materiais e biotecnologia.

Várias perguntas, algumas vezes até mesmo aparentemente antagônicas, marcaram os anos 90. Começou com: "Quantos trabalhos você já publicou?" Rapidamente passou para: "Quantos trabalhos você publicou este ano?" E, com velocidade ainda maior, começou-se a indagar: "Qual o fator de impacto das revistas nas quais você publica?", deslanchando daí para: "Objetivamente, sua pesquisa serve para quê? Você tem alguma interação com o setor produtivo?"

Destaque-se que todas essas perguntas, bem ou mal, tiveram que ser respondidas em um cenário caracterizado pela descontinuidade nos financiamentos para a pesquisa - mormente pelas agências federais (Finep e CNPq) - por ataques veementes à imagem da universidade pública $\mathrm{e}$ por vertiginosa substituição de quadros, motivada pela corrida às aposentadorias. Não obstante, o mais surpreendente é que, superando todas essas dificuldades, a produção científica aumentou, crescendo de modo significati- vo. Na década de 90, praticamente dobrou-se a produção em relação à de 80 , ultrapassando $1 \%$ da geração da ciência mundial, medida pela quantidade de publicações indexadas.

Os anos 2000 têm sido marcados por rápidas mudanças no cenário do financiamento à pesquisa no país. Existem sinais positivos de recuperação do financiamento federal, via editais universais e indutores, sobretudo em conseqüência do programa de Fundos Setoriais e NãoSetoriais e pela criação de redes, como os Institutos do Milênio. Entretanto, a maioria desses novos mecanismos aponta para uma ênfase em grandes projetos, com investimento de somas vultosas de recursos em um número reduzido de grupos de pesquisa. Cabe analisar criticamente essa mudança no modo de financiamento à pesquisa, sobretudo em função do relativo abandono a que estão relegando os mecanismos tradicionais de financiamento de projetos de pequena monta. O chamado "balcão" permitiu avanços importantes e viabilizou a consolidação dos chamados grupos de excelência, que hoje se privilegiam com os novos programas das agências.

Esse cenário coloca-se perante uma situação nova que traz, implicitamente, outras perguntas. Parece que se está diante de uma mudança de paradigma. Na hipótese otimista, estar-se-ia, afinal, deixando, passo a passo, de fazer uma ciência majoritariamente reflexa em favor de uma ciência com maior autonomia, relevância, liderança local e, sobretudo, com implicações conseqüentes para o desenvolvimento científico, tecnológico, social e cultural do Estado e do país.

Admitindo-se tal cenário, a organização da pesquisa científica por certo deverá passar por mudanças, havendo a necessidade de nova percepção da importância da pesquisa científica e tecnológica, que certamente não se resume a mera questão de financiamento, ainda que ninguém ouse negar essa forte dependência. Acredita-se que a dimensão estratégica será decisiva nessa nova fase. Daí terse que trabalhar com uma antevisão de um desenvolvimento verdadeiramente sustentável e não divorciado da realidade de toda a sociedade.

\section{UM PAÍS COM CIÊNCIA OU APENAS UM PAÍS COM CIENTISTAS?}

Com o avanço das fronteiras do conhecimento humano, a ciência proporciona aos povos que participam de fato de seu desenvolvimento melhor qualidade de vida. Isso é alcançado mediante libertação do homem quanto às ne- 
cessidades básicas de sobrevivência e da conseqüente sofisticação da atividade humana em seus aspectos sociais, econômicos, culturais e artísticos. Em última instância, fazer ciência é viver na plenitude a aventura do homem sobre a Terra. Os povos que não participam do desenvolvimento científico estão, em grande medida, alijados dos avanços nos padrões de qualidade de vida e são economicamente subalternos em relação aos povos que lideram os avanços do conhecimento. Reverter esta situação não é tarefa fácil já que criar uma cultura científica exige inúmeros investimentos em educação e cultura, o que é agravado pelas carências advindas da dificuldade que essas sociedades têm em criar riquezas sem o insumo principal para isso, que é o conhecimento. Encontrar modos de romper esse círculo vicioso é o grande desafio das sociedades dos países em desenvolvimento como o Brasil.

Em uma aproximação muito grosseira, mas ilustrativa, poder-se-ia dizer que o mundo está hoje dividido em duas partes. Por um lado, existe o tecnologicamente avançado, cuja característica principal é o alto padrão de domínio da ciência e da inovação tecnológica. Do outro lado, o Terceiro Mundo, que não dispõe do domínio da ciência e da tecnologia. Ou seja, um Primeiro Mundo que pensa cientificamente, cria, inventa, produz, descobre, empresta ou sonega sua tecnologia, e um Terceiro que viaja, se comunica, se diverte, trata a saúde e morre, utilizando-se das roupas, veículos, telefones, Internet, televisão, esportes, medicamentos e armas que inventa o Primeiro.

Mediante os meios de comunicação, o Terceiro Mundo só percebe a ciência em seus aspectos mais externos: manchetes de jornal, celebrações, premiações, recepções, discurso de autoridades e congressos científicos que reúnem a elite da inteligência. Nesse contexto, a ciência aparece como ferramenta miraculosa para tirar o país do atraso, da miséria e da desesperança. O político e os tomadores de decisão em geral compartilham dessa visão e concluem que bastaria financiar algumas centenas, ou milhares de pesquisadores para "pegar o bonde" do progresso, da abundância e da felicidade. Quantas vezes não se escuta, a cada descoberta importante no Primeiro Mundo, a famosa frase: "o Brasil não pode perder o bonde de... (o que quer que seja)". Infelizmente, o bonde nunca é alcançado, ou quase nunca.

Essa visão ingênua, que considera a ciência patrimônio de um seleto grupo de cidadãos, dos quais cabe esperar o milagre e o fim da miséria, encobre um erro de perspectiva fundamental. Um país não faz ciência apenas aplicando quantidades variáveis de dinheiro em cientistas e la- boratórios. Esses investimentos são necessários, mas não suficientes. Se bem-sucedidos, geram bons pesquisadores, componente indispensável para expansão das fronteiras do conhecimento. No entanto, a experiência dos últimos séculos revela que, para um país ter ciência, é necessário que sua sociedade possua uma visão do mundo norteada pela certeza de que a ciência, assim como seu produto, é a verdadeira geradora de bem-estar e progresso. Não se pretende aqui afirmar que essa visão seja necessariamente a de cada um dos cidadãos, mas, é evidente, que seja a dos que decidem os rumos do acontecer nacional: dirigentes políticos, empresariais e sindicais; forças armadas, organizações públicas ou privadas de produtores e consumidores; e, sobretudo, dos que, em todos os níveis, planejam e implementam o sistema educativo.

A outra visão da ciência, a que faz dela uma parte do marketing político, é apenas "ciência para inglês ver". Essa intrigante expressão, que tem origem na época da escravatura, é muito conveniente para adjetivar parte da pesquisa feita no Brasil. Nela, a simples aquisição de equipamentos científicos sofisticados é considerada uma conquista científica em si mesma. Esses equipamentos são, algumas vezes, exibidos a visitantes como se fossem resultados significativos da pesquisa, e não apenas ferramentas de trabalho. Por trás dessa visão, está a crença de que a ciência é feita por sofisticados aparatos e não por homens, e que basta equipar modernamente um laboratório para que comecem a surgir resultados de pesquisa. A experiência indica, no entanto, que o componente fundamental do acontecer científico é sempre o recurso humano.

Para conseguir um país com ciência, a educação universal, obrigatória e de qualidade é peça fundamental para que a população acredite que o bem-estar da sociedade depende da procura constante pela apropriação do saber. Uma população integrada na moderna sociedade da informação exige massa crítica de pesquisadores recrutados em um universo abrangente da população com acesso à educação superior e um sistema produtivo comprometido com o progresso. Portanto, a existência de ciência num país depende mais da visão do mundo que sua sociedade possui, do que da fração do PIB aplicada na compra de telescópios, espectrômetros, computadores, e outros equipamentos necessários à pesquisa. Essa visão faria, por exemplo, com que câmaras empresariais e sindicatos saíssem em defesa imediata de escolas, colégios e universidades cada vez que o poder central os sufocasse economicamente, ou de alguma outra forma. Eles também fariam 
ouvir sua voz para impedir que educadores e professores construíssem sistemas de privilégios corporativos.

Ter uma sociedade com cultura científica capaz de gerar conhecimento original não é o mesmo que ter alguns poucos grandes cientistas. Com recursos expressivos aplicados de forma continuada e um programa de formação de pesquisadores no exterior, um país pode gerar, em pouco tempo, grupos de pesquisa altamente qualificados, com alguns pesquisadores de nível internacional capazes de obter importantes prêmios acadêmicos. Entretanto, esses grupos estarão inteiramente desvinculados da realidade social do país e terão poucas chances de fertilizar, com suas descobertas, o sistema industrial e de serviços e gerar emprego e renda. Tem-se hoje no mundo vários países nessas condições, países cujos cientistas receberam até prêmios Nobel, mas cuja população continua a viver majoritariamente na miséria e na ignorância.

O grande desafio da sociedade é promover o crescimento econômico e a redução da desigualdade social, e não há dúvida de que o aumento do nível de escolaridade geral da população é parte essencial desse processo. Mais escolaridade de qualidade e a conseqüente integração de maior parcela da população ao esforço do país em ciência e tecnologia é condição básica para a participação de todos os brasileiros em uma economia moderna, em uma sociedade verdadeiramente democrática.

\section{CIÊNCIA E INOVAÇÃO}

Um engano que se propaga nos dias atuais é a crença que o produto da ciência é o invento, ou a inovação tecnológica. Nesse sentido, propala-se a idéia que, para se sair do marasmo, deve-se inventar e inovar mais, a exemplo do que acontece na Coréia. Por trás dessa afirmação está a ilusão de que a exportação de produtos com maior valor tecnológico agregado conseguirá pagar a enorme dívida social que o país tem com a população marginalizada há séculos. Entretanto, uma rápida navegação na Internet com a palavra-chave "patentes" indica que há países, como os países nórdicos, por exemplo, cujo alto nível de bem-estar e desenvolvimento pouco tem a ver com o número de patentes que registram anualmente. Existem países periféricos, inclusive na América Latina, com estrutura social bem menos perversa do que a do Brasil, que não possuem um sistema de pós-graduação e pesquisa tão sofisticado quanto o brasileiro. Em outras palavras, a desigualdade social e o abandono das classes menos favorecidas no Brasil não são conseqüência direta da fal- ta de investimentos em laboratórios ou do atraso na formação de pesquisadores. Uma rápida análise da natureza dos graves problemas estruturais que hoje afligem a sociedade brasileira indica que eles não requerem uma ciência de ponta para sua solução. A ciência e a tecnologia que se possui nesse momento poderiam, em um contexto social menos perverso, dar conta da maioria desses problemas básicos de forma satisfatória.

No entanto, o Brasil não pode deixar de fazer pesquisa. Mais ainda, não pode deixar de incrementar sua capacidade de pesquisa, em razão dos desafios do mundo contemporâneo. Cabe aqui uma reflexão sobre a importância da pesquisa no contexto brasileiro. É evidente que a pergunta: "Que tipo de pesquisa?", merece ser amplamente debatida. A pesquisa será essencial para se enfrentar os problemas que o século XXI apresenta em todos os campos. Mesmo na área de Saúde, em que grande parte dos problemas atuais da população brasileira se resolveria com saneamento, alimentação e bom-senso, o novo século desafia com os "novos dramas" das doenças emergentes, dos germes oportunistas resistentes a fármacos, das doenças degenerativas da crescente população idosa e das múltiplas implicações da terapia gênica. Seria suicídio o país se autocondenar a uma posição de cliente ignorante em relação à nova ciência e tecnologia, pois clientes ignorantes pagam mais caro, compram mal e são mal-atendidos. A situação é ainda mais premente no campo das ciências humanas. Os tremendos problemas sociais que se enfrenta requerem não apenas vontade política e mudanças econômicas, mas também compreensão das circunstâncias e dos fatores do atraso. Ter a percepção da realidade de modo objetivo e científico é condição necessária, mas não suficiente. Pseudo-soluções simplistas apenas perpetuam a frustração e o desânimo.

Um país que possua ciência - não medida pela fração do PIB que investe na parafernália científica, mas no sentido anteriormente descrito -, é um país que sabe de seus problemas e pode solucioná-los. Ele é capaz de antecipar questões, pois sabe mais sobre ele próprio do que os outros países, o que é característico da superação do subdesenvolvimento. Assim, ele está mais bem aparelhado na busca de soluções que permitam superar dificuldades de natureza econômica, tecnológica, ou social.

\section{QUALIDADE E RELEVÂNCIA DA PESQUISA}

Toda pesquisa científica busca atingir, de forma subjacente, dois objetivos: qualidade e relevância. A qua- 
lidade refere-se ao âmbito interno da área na qual a pesquisa desenvolve-se. Trata-se de sua profundidade, abrangência, à medida que lança luz sobre diferentes assuntos, e que resolve problemas e desafios históricos. Em geral, os que opinam sobre qualidade são os especialistas da mesma área de pesquisa, segundo o conhecido "juízo dos pares". A relevância relaciona-se com a aplicabilidade a áreas externas à do desenvolvimento da pesquisa e com sua importância para a sociedade.

Os cientistas costumam fixar-se essencialmente na qualidade, embora procurem destacar a relevância quando buscam ser contemplados por algumas linhas específicas de financiamento. Tanto a qualidade quanto a relevância são medidas de modo imperfeito, e não poderia ser de outra forma, pois não existe uma maneira exata para medir uma ou outra. Portanto, toda medida é aproximada e pode apenas indicar parâmetros que, de acordo com o bom-senso, parecem bastante correlacionados com uma ou outra. Existem exemplos espetaculares de erros cometidos pelo sistema atual de avaliação tanto relativamente à qualidade como à relevância. É necessário ter presente essa incerteza essencial da avaliação, pois agir com base em certezas absolutas, quando elas inexistem, conduz a erros trágicos. A avaliação da qualidade dá-se essencialmente pelo julgamento de pares, quando o resultado da pesquisa é submetido para publicação. Esse sistema apresenta dinâmica própria: é imperfeito, está sujeito a oportunismos, a semifraudes, a troca de favores e a diversos tipos de manipulação. Entretanto, ainda não foi encontrado nada melhor. De fato, pode-se dizer, com certa dose de ironia, que os incontáveis defeitos que apresenta são, se bem apreciados, virtudes, pois permitem que cientistas que não são bem-sucedidos desqualifiquem o sistema de avaliação por seus óbvios defeitos, às vezes com razão. Obtêm, assim, estímulo para continuar trabalhando apesar de os fracassos, estímulo que não teriam se tivessem sido rejeitados por um sistema perfeito.

Não é possível prescindir da avaliação da qualidade, pois o risco seria incorrer em avaliações muito piores. Em sua versão mais simplista, a avaliação que se faz hoje consiste na contagem de publicações e citações. A outra questão é a "relevância". Com isso refere-se aos critérios que vêm de fora da área, já que uma relevância "interna" confundir-se-ia com o que se denomina "qualidade". A correlação entre qualidade e relevância existe, mas não deve ser superestimada. Quase tudo o que tem muita qualidade torna-se relevante e, provavelmente, nada do que não tem qualidade terá alguma relevância. No entanto, existem notáveis exceções. O fato é que a relevância julga-se com base em um ponto de vista externo à área. Quando se julga relevância, o resultado é, em geral, o financiamento, bem como o julgamento de qualidade tem por resultado a publicação, o prêmio, ou a citação elogiosa.

Quando a universidade distribui recursos internamente, estimula áreas de pesquisa, monta laboratórios ou contrata, ela se envolve inevitavelmente com julgamentos de qualidade e relevância. Hoje, assiste-se a uma alteração na política nacional de financiamento, cujo critério dominante parece deixar de ser a qualidade e passa a ser a relevância. Entretanto, como o julgamento da qualidade, o julgamento da relevância está sujeito a erros terríveis, talvez ainda maiores. É de fundamental importância que o conjunto das ações e programas de apoio seja balanceado, não inviabilizando os programas de fomento tradicionais, que não são condicionados a critérios de relevância direta e imediata - perigo embutido no novo modelo.

Em vista da impotência para julgar de maneira equânime, as receitas para errar o menos possível devem manter o equilíbrio entre critérios de qualidade e relevância e ter como ingredientes mecanismos formais democráticos, imparciais (julgamentos sempre externos) e eticamente irrepreensíveis. Tratando-se de errar, é melhor errar imbuído de boas intenções.

\section{Publicar ou Não Publicar}

Tem sido recorrente na comunidade universitária brasileira o debate sobre a importância - ou não - das publicações científicas stricto sensu. Cada vez que a questão da avaliação da pesquisa é abordada o debate ressurge, acalorado. De um lado, há os que defendem que a única forma de avaliar o trabalho científico é mediante publicações em periódicos com conselho editorial, critérios de avaliação por pares rigorosos, indexados nas melhores bases de dados, de circulação internacional e com índices de impacto significativos. De outro, há os que apontam especificidades de suas áreas de pesquisa, suposta incompatibilidade entre a relevância para a sociedade e a possibilidade de gerar publicações, uma possível desvalorização das atividades de ensino e extensão, a importância da produção tecnológica - cujo sigilo impediria a publicação - e outros argumentos para relativizar ou mesmo desacreditar completamente a avaliação por publicações e seu impacto na forma de citações.

Em vez de enumerar argumentos contra e a favor de uma das duas teses, cabe refletir sobre o mérito de tal 
debate. Para analisar este ponto, é importante analizar a gênese das publicações científicas. Periódicos científicos surgiram desde as cartas trocadas por pesquisadores e certamente foram eles que permitiram o notável desenvolvimento científico verificado nos últimos séculos, desde que as Philosophical Transactions da Royal Society e o Journal de Scavans começaram a ser publicados em 1665. A revolução da Internet talvez torne os periódicos em papel anacrônicos em pouco tempo, substituindo-os por periódicos eletrônicos, que permitem trazer não apenas textos como também imagens e sons, e por sítios eletrônicos, em que grupos de pesquisa podem expor em tempo real os resultados de suas pesquisas; mas a publicação como forma de troca de informação entre cientistas, avalizada pelos pares, certamente continuará a ser com a ética um fundamento da nossa atividade.

Chega a ser espantoso que alguém lance mão do argumento da inexistência de periódicos em sua área como pretexto para não publicar quando, já em 1996, o Ulrich's International Periodicals Directory listava a existência de 165 mil periódicos científicos, número que certamente só aumentou desde então. Não há como ser "autista" em ciência ou na busca do conhecimento em geral. Isso, é certo, vale também para as técnicas de ensino e ainda mais para a tecnologia. Se existe uma nova área de pesquisa com alguma relevância que ainda não esteja sendo divulgada em periódicos, faz parte da missão do pesquisador encontrar os periódicos que se interessem em incorporá-la às suas áreas de interesse ou mesmo criar novos, nos quais essas pesquisas possam ser discutidas pela comunidade científica que a ela se dedica. Esses periódicos devem, é evidente, buscar atingir outros pesquisadores que atuem na área e não apenas satisfazer o ego de quem publica e gerar linhas em currículos e números em relatórios.

No entanto, cabe lembrar que existe a possibilidade de publicar livros científicos. Diferentemente dos livros didáticos, cujo valor está na forma de apresentação de temas conhecidos e no aspecto comercial, os livros científicos talvez sejam a forma mais nobre de publicação. Também nesse caso é necessário avaliar o corpo editorial, a seriedade da editora e o impacto que o livro científico tem. O simples fato de publicar um livro não tem um mérito garantido a priori, uma vez que existem até editoras que sobrevivem dos pagamentos que fazem autores vaidosos para publicar suas obras.

As publicações são particularmente importantes no início da carreira, para que o pesquisador exponha-se e exponha seu trabalho à comunidade científica de sua área. Esta interação traz possibilidades de intercâmbio absolutamente essenciais à atividade de pesquisa. Com o passar do tempo, uma maneira de avaliar o impacto do trabalho científico de um pesquisador ou de um grupo de pesquisa consiste em medir as conseqüências de suas publicações (e por isso é necessário que haja publicações) em forma de convites para: coordenar sessões técnicas e ministrar palestras em eventos científicos importantes; ser professor ou pesquisador visitante (pago por quem convida, não com bolsas do governo brasileiro) de universidades e institutos de pesquisa de prestígio; integrar conselhos científicos e editoriais de eventos e de periódicos; árbitro de agências de fomento do país e do exterior e prêmios acadêmicos outorgados por sociedades científicas e outras instituições (excluídos os de cunho político).

Ainda que menor que o número de periódicos de outras áreas, o número de periódicos nas áreas tecnológicas é expressivo. Um levantamento recente feito entre periódicos eletrônicos (Wells ) aponta que $8 \%$ do total eram de periódicos em tecnologia, contra $37,3 \%$ em ciências sociais, $20,8 \%$ em ciências da vida, $16,7 \%$ em artes e humanidades, $16,2 \%$ em ciências exatas e $1 \%$ em áreas não definidas. Aliás, a própria distinção entre pesquisa básica e aplicada vem perdendo nitidez. A distinção pode estar hoje mais na intenção original da pesquisa que em seus resultados, uma vez que a distância entre pesquisa de ponta e aplicação tecnológica vem diminuindo muito rapidamente. Se é verdade que alguns resultados da pesquisa tecnológica são sigilosos devido aos interesses econômicos imediatos envolvidos, é difícil supor uma pesquisa tecnológica relevante que não seja publicável parcialmente, com a devida filtragem das informações sensíveis. Esta é uma prática corrente e que explica o crescente número de periódicos de cunho tecnológico.

Em última instância, uma instituição é avaliada pelos produtos que gera e pelas funções que desempenha na sociedade. Da universidade espera-se, sobretudo, que forme profissionais e pesquisadores bem preparados e com sólidos valores éticos e de cidadania e que gere conhecimento - ciência, tecnologia, humanidades e arte - voltado à solução de problemas relevantes para a humanidade e para a sociedade que a financia. A competência dos grupos de pesquisa e dos pesquisadores individualmente só pode ser avaliada pelos seus pares. Os aspectos ligados ao ensino e às atividades de extensão são avaliados diretamente pela sociedade, que forma seu julgamento quan- 
do do desempenho dos profissionais que a universidade forma e da qualidade dos serviços que ela presta.

\section{Recrutando Docentes}

A qualidade da pesquisa feita numa universidade depende, na essência, dos pesquisadores que nela atuam e do ambiente institucional propício à pesquisa científica relevante e de qualidade. Portanto, uma das questões centrais é a maneira como a universidade contrata seus docentes. Nos próximos anos, com o crescente número de aposentadorias e com a expansão esperada e desejada no número de alunos de graduação, haverá a necessidade de fazer novas contratações em número expressivo. Existem riscos e oportunidades nesse processo de renovação do corpo docente.

A questão estratégica mais importante para uma política de contratações tem a ver com a pergunta: "que espécie de universidade gostaríamos de ter daqui a uma ou duas décadas?" Ou, ainda, "que espécie de universidade podemos construir para dar o maior retorno à sociedade, levando em consideração os recursos disponíveis e as limitações conjunturais?"

O problema extrapola a simples questão de uma sistemática de substituição de docentes ou em função das necessidades da carga didática. Ele inclui:

- a identificação de temas de relevância científicotecnológica que não estão sendo desenvolvidos apropriadamente na instituição;

- a prospecção de temas relevantes para o desenvolvimento social e cultural da região e do país que não estejam sendo abordados na instituição;

- a elaboração de uma política para a correção dessas deficiências.

Hoje se sabe contratar jovens doutores que desenvolverão suas pesquisas nos diferentes grupos ou laboratórios existentes nas unidades e institutos com um razoável grau de eficácia. Ou seja, sabe-se preencher quadros no início de carreira. Essas contratações resultam, geralmente, de solicitações de grupos de trabalho já consolidados. Com freqüência referem-se à incorporação de elementos oriundos da própria equipe proponente.

Entretanto, a Universidade Brasileira não tem sabido, em geral, contratar docentes com um número significativo de anos de experiência em temas que sejam de interesse para a universidade e para a sociedade. Em outras palavras, não se sabe atrair potenciais líderes acadêmicos para iniciar novos grupos de pesquisa. Só se consegue oferecer um salário, o que geralmente não constitui atrativo suficiente. Essa característica do sistema de contratação, bem como as considerações que seguem, não são patrimônio só da Unicamp, mas do conjunto das universidades públicas brasileiras.

Como resultado dessa política (ou da falta de política), há o sério risco de congelarem-se tematicamente algumas unidades de ensino e pesquisa. Nas últimas duas décadas, embora tenham surgido inúmeras novas áreas de pesquisa, a criação de novos grupos de pesquisa na Unicamp deveu-se, muitas vezes, a divisões internas de grupos já existentes. É obvio que não se pode ambicionar ter todas as especialidades em uma universidade, mas a escolha de quais entre elas serão desenvolvidas não deveria ser obra do acaso, mas de um planejamento estratégico. Para ter uma instituição dinâmica, capaz de acompanhar a par e passo o desenvolvimento técnico-científico e artístico internacional e servir melhor a sociedade que a sustenta, é essencial aperfeiçoar o processo de atração e fixação de novos pesquisadores na universidade.

Uma das maneiras possíveis para atrair pesquisadores de grande potencial seria o oferecimento de um "enxoval", negociado institucionalmente. Esse enxoval contraria recursos para custear as pesquisas por alguns anos incluindo verbas para equipamentos, material de consumo, viagens, bolsas e, por que não, até mesmo um benefício salarial suplementar, nos moldes da bolsa de produtividade do CNPq. É instrutivo observar que a competição entre as instituições para atrair os melhores pesquisadores, prática saudável que é corrente de uma maneira ou de outra nos países mais desenvolvidos, é praticamente inexistente no Brasil. Herança de uma época ainda recente, quando o número de boas instituições era bastante reduzido, a imobilidade que caracteriza a carreira do pesquisador no país requer novos mecanismos capazes de promover maior fluidez ao sistema.

A contratação temporária por um período de alguns anos e terminando em um concurso público para efetivação é um mecanismo adequado desde que, aqui novamente, as bancas, tanto de seleção inicial como de concurso, tenham forte participação externa e sejam definidas por critérios puramente acadêmicos. Esta sistemática evita a estabilidade precoce, verdadeira camisa-de-força para a capacidade criativa da universidade.

De qualquer modo, o essencial é manter vivo o objetivo de contratar os melhores pesquisadores levando em conta os objetivos institucionais, o que requer uma inten- 
sa e permanente tarefa de conscientização. Contratações não devem ser feitas apenas para repor aqueles que se aposentam ou pedem demissão, nem apenas para cobrir necessidades de carga didática. A definição dos departamentos ou unidades que fazem jus a uma vaga deve ser feita com base em propostas bem fundamentadas que contemplem os aspectos de pesquisa e ensino. Essas propostas devem ser analisadas por comissões com forte participação de membros externos à universidade, cuja indicação deve ter critérios exclusivamente de mérito e competência.

\section{O "custo Brasil" na Pesquisa}

Como mencionado anteriormente, a Unicamp vem conseguindo um crescimento contínuo de sua produção acadêmica. Isto é também verdade para outras universidades públicas paulistas e de outros Estados. O aumento da produção científica está associado ao crescimento da pós-graduação e ao financiamento da pesquisa pelas agências governamentais de fomento, particularmente no Estado de São Paulo, onde a Fapesp proporciona financiamentos de grande monta de forma estável, mediante julgamentos cuidadosos por pares, feitos com base no mérito científico.

Essa realidade poderia sugerir que a situação na Unicamp, como em outras boas universidades públicas do país - particularmente as estaduais paulistas - não seja muito diferente das boas universidades de países mais desenvolvidos e que os principais desafios já tenham sido superados. No entanto, quando se analisa os índices de produtividade, constata-se que ainda se está longe dos números daquelas universidades, sobretudo no que se refere ao impacto das publicações.

Quais seriam as razões dessa disparidade? O que dificultaria as pesquisas e comprometeria o desempenho? Que problemas preocupam o jovem pesquisador que realiza um produtivo estágio de pós-doutorado no exterior, no momento de seu retorno ao Brasil? Sabe-se que parcela de produtivos pós-doutores brasileiros perde o brilho ao retornar à instituição de origem. Alguns produzem ciência de qualidade somente nos períodos que passam no exterior. É fato também que pesquisadores seniores muitas vezes temem retornar ao Brasil apesar de tentadoras promessas de emprego estável em nossas melhores universidades.

Não é difícil para um pesquisador brasileiro, com passagens por boas universidades do exterior, enumerar uma série de problemas, em sua maioria de natureza administrativa e de infra-estrutura, que dificultam as atividades de pesquisa. Elas representam o equivalente ao que se convencionou chamar, nas empresas, de "custo Brasil". Neste caso, trata-se de dificuldades de organização, de cultura institucional e de infra-estrutura.

A universidade é uma instituição relativamente jovem no Brasil. Isto é verdade não apenas para a Unicamp, que nasceu na década de 60 , mas também para as mais antigas universidades, onde a capacidade de fazer ciência de forma mais disseminada e sistemática tem, salvo raras exceções, uma história de não mais que trinta anos. Ainda na sua adolescência, portanto, nossas instituições universitárias ressentem-se de algumas opções que fizeram em relação à forma de governo e que já deram mostras de inadequação. A falta de uma clara distribuição de responsabilidades, com a conseqüente diluição excessiva dos processos decisórios, fenômeno conhecido por "democratismo", associado a certo corporativismo, dificulta tanto a cobrança de desempenho quanto a valorização do mérito na manutenção e reposição dos quadros. Não há limites precisos quanto às exigências em relação às obrigações e competências esperadas de seus servidores. Isso gera uma situação de "marasmo funcional". O resultado final é que a produtividade acadêmica está muito mais relacionada, em todos os níveis, a iniciativas e ações individuais que a uma cultura institucional.

A carência de apoio técnico e administrativo competente transforma o docente em uma espécie de curinga, que tem que se ocupar de tarefas para as quais não está preparado e que nada acrescentam à sua atividade acadêmica. Contabilista das prestações de contas junto à universidade e às agências de financiamento, o docente é ainda administrador de pessoal, prefeito de campus, gerente de hospitais universitários e de setores de apoio como informática, audiovisual, bibliotecas e biotérios.

No dia-a-dia do docente existem comissões e mais comissões que fazem longas reuniões nas quais o principal resultado é agendar a data da próxima reunião e cuja função poderia ter sido cumprida por um competente funcionário técnico-administrativo ou de apoio científico ou didático com o aval de um Chefe de Departamento ou Diretor de Instituto.

De maneira geral, a infra-estrutura dos laboratórios é precária devido, sobretudo, ao crescimento não planejado das instituições e à falta de uma manutenção adequada. Como exemplo, pode-se citar redes elétricas inadequadas para suportar a demanda de equipamentos científicos que, com o tempo, amontoam-se, tornam-se ineficientes e com vida útil mais curta, o que implica gran- 
des prejuízos para o andamento das pesquisas experimentais e desperdício de recursos públicos. O longo tempo gasto na importação de materiais de consumo e equipamentos pode representar verdadeiro marca-passo nas pesquisas.

Certamente, um oportuno, desejado e factível salto de qualidade dependerá também da solução desses problemas de infra-estrutura e, sobretudo, de organização.

\section{CONSIDERAÇÕES FINAIS}

Nesta contribuição, analisou-se a natureza da ciência e da apropriação e uso do conhecimento numa sociedade moderna com especial ênfase na situação de países periféricos, especialmente o Brasil. Apesar dele possuir um conjunto expressivo de cientistas de bom nível e de injetar recursos relativamente vultosos, levando em conta sua realidade social, no financiamento à pesquisa, a ciência $\mathrm{e}$ a mentalidade científica ainda não estão incorporadas de maneira plena na sociedade. Essa situação deriva principalmente da tremenda exclusão social de grande parte da população. O sistema educacional deixa fora da educação formal de qualidade, particularmente da educação para a ciência, grande parte de nossa juventude. Nesse sentido, constata-se que não basta injetar recursos em programas que visam equipar alguns laboratórios considerados de excelência. Esses programas, por si só, não são suficientes, pois os problemas enfrentados no desenvolvimento da ciência e no aproveitamento dos frutos da pesquisa científica são quase sempre problemas de recursos humanos.
Conseqüentemente, o desafio principal que o Brasil enfrenta parece ser o estabelecimento de um sólido sistema de educação pública que permita incluí-lo em sua totalidade no desenvolvimento de uma ciência não dissociada dos grandes problemas nacionais. Para que isso aconteça, é preciso uma grande mobilização de toda a sociedade, pois a transformação exigida é essencial para que os recursos investidos na pesquisa possam, de fato, frutificar, tanto em relação à contribuição que a ciência dará para o avanço do conhecimento como em relação à melhoria da qualidade de vida de nossa população.

\section{NOTA}

O Fórum de Reflexão Universitária foi criado em 1999 por iniciativa do Professor Ivan Chambouleyron, Pró-Reitor de Pesquisa da Unicamp, para criar um espaço de discussão acadêmica dos problemas do sistema de ensino superior. O Fórum é composto pelos Professores: Anibal Vercesi (Faculdade de Ciências Médicas), Daniel Joseph Hogan (Instituto de Filosofia e Ciências Humanas), Ivan Chambouleyron (Instituto de Física 'Gleb Wataghin'), José Mario Martínez (Instituto de Matemática, Estatística e Computação Científica), José Roberto de França Arruda (Faculdade de Engenharia Mecânica), Oswaldo Luiz Alves (Instituto de Química), Paulo Arruda (Instituto de Biologia) e Rodolfo Hoffmann (Instituto de Economia). E-mail para contato com os autores: ivanch@ifi.unicamp.br.

\section{REFERÊNCIA BIBLIOGRÁFICA}

WELLS, A. "Exploring the development of the independent, electronic, scholarly journal". Publicação eletrônica da University of Sheffield: $<$ http://panizzi.shef.ac.uk/elecdiss/ed10001/index.html $>$. 